\title{
The use of small-Unmanned Aerial Systems for high resolution analysis for intertidal wetland restoration schemes
}

Jonathan Dale ${ }^{1}$, Niall G. Burnside ${ }^{2}$, Conor J. Strong² and Heidi M. Burgess ${ }^{2}$

${ }^{1}$ Centre for Agroecology, Water and Resilience (CAWR), Coventry University, Coventry, CV8 3LG, UK.

${ }^{2}$ School of Environment and Technology, University of Brighton, Brighton, BN2 4GJ, UK.

*Corresponding Author:

Jonathan Dale

School of Energy, Construction \& Environment, John Laing Building, Much Park Street Coventry University, Coventry, CV1 5FB, UK.

Email: jonathan.dale@coventry.ac.uk

Submitted to Ecological Engineering

Keywords

Managed realignment; creeks; intertidal morphology; small-unmanned aerial system (sUAS); structure-from-motion (SfM)

Published in Ecological Engineering, Volume 143, 2020 https://doi.org/10.1016/j.ecoleng.2019.105695 Authors' pre-print version 


\section{Abstract}

2

3

Coastal and estuarine wetlands provide a range of important ecosystem services, but are currently being damaged and degraded due to human activities, reduced sediment supply and sea level rise. Managed realignment (MR) is one approach used to compensate for the loss of intertidal habitat, however saltmarshes in MR sites have been recognised to have lower biodiversity than natural environments. This has been associated with differences in the physical functioning including the sediment structure, reduced hydraulic connectivity, and lower topographic variability such as the abundance of intertidal creek networks. Intertidal morphology, including creek networks, play an important role in supporting and regulating saltmarsh environments through the supply of sediment, nutrients and water, and in draining intertidal marshes. However, there is a lack of empirical data on the formation and evolution of topographic features and variability in saltmarsh environments. This is likely to be due to creek networks in natural marshes already being in a state of quasi-equilibrium, making MR sites an ideal environment to investigate creek development. However, traditional remote sensing techniques (such as LiDAR) tend to be relatively expensive, infrequent and at a coarse resolution meaning small, but important (cm-scale), changes are often missed. This study advances the ability to detect these small scale changes by demonstrating the suitability and potential applications of using the emerging photogrammetric method Structure-from-Motion (SfM) on images taken using a smallUnmanned Aerial System (sUAS). Three surveys from a rapidly changing, near-breach site were taken at the Medmerry Managed Realignment Site in July 2016, September 2017 and July 2018. A suitable degree of confidence was found between the modelled surface and independent check points (vertical root-mean-square-errors of 0.0245, 0.0704 and 0.1571 for 2016, 2017 and 2018 respectively). DSMs of Difference (DoD) analysis was performed to evaluate elevation change, with areas experiencing up to $85 \mathrm{~cm}$ of accretion between 2016 and 2018. However, when considering the error associated with both surveys, between 2016 and 2017 , only $34.39 \%$ of the survey area experienced change above the level of detection (LoD). In contrast, 76.97 \% experienced change greater than the LoD between 2017 and 2018. Stream order analysis classified the creek networks into five orders in 2016 and four orders in 2017 and 2018, with 2016 having a higher abundance (291 in 2016 compared to 117 (2017) and $112(2018))$ and density $\left(0.44 \mathrm{~m} / \mathrm{m}^{2}\right.$ in 2016 compared to 0.27 $\mathrm{m} / \mathrm{m}^{2}$ in both 2017 and 2018) of creek networks. These results provide an innovative high resolution insight into the evolution of restored intertidal wetlands, and suggest that SFM analysis of images taken using a sUAS can be a useful tool with the potential to be incorporated into studies of MR and natural saltmarsh sites. sUAS analysis can, therefore, advance the management of these environments to ensure the provision of ecosystem services and to protect against future anthropogenic activity, sea level rise and climate change. 


\section{Introduction}

Coastal and estuarine wetlands, such as saltmarshes, have declined globally by approximately 25 to $50 \%$ over the last 150 to 300 years (Lotze et al., 2006), with approximately 1 to $2 \%$ of saltmarsh lost each year (Duarte et al., 2008). This is despite the recognition in recent years of the importance and range of ecosystem services provided by these environments (e.g. Costanza et al., 1997). To compensate for the loss of intertidal habitats, a number of restoration and compensation schemes have been implemented. Managed realignment (MR) is one of the most common saltmarsh restoration schemes, and has been implemented widely across Europe and the USA. Yet, despite the relatively quick colonisation of these schemes by saltmarsh plants and invertebrates (Garbutt et al., 2006; Mazik et al., 2010; Wolters et al., 2005), MR sites commonly have different species composition in comparison to natural sites (Mossman et al., 2012), and a lower diversity of important targeted species. These differences are likely to affect the ecosystem services provided by MR schemes and have been associated with a failure to reconstruct the physical functioning and processes which occur in natural saltmarsh environments. These processes include differences the sediment structure, geochemical profiles, hydraulic connectivity (Spencer et al., 2017; Tempest et al., 2015) and topographical variability such as the density and complexity of creek networks (Lawrence et al., 2018).

In natural intertidal environments, creek networks play an important role in the physical structure and functioning of the ecosystem. Creek networks connect the upper saltmarsh to the lower elevation mudflat and the open coast, acting as a conduit for water, sediment and nutrients, regulating site drainage, dissipate wave and tidal energy, and providing habitats for fish species (e.g. Reed et al., 1999; Sanderson et al., 2001). The formation of creek networks has been studied through morphodynamic modelling (e.g. Fagherazzi and Furbish 2001), which suggest that creek formation is initially a relatively rapid process which gradually slows as creeks stabilise. However, there are relatively few empirical field studies of creek formation to validate these models, probably due to most creek networks already being in a state of quasi-equilibrium (e.g. Marani et al., 2003; Vandenbruwaene et al., 2012). Therefore, newly inundated intertidal environments, such as MR sites, may provide the best opportunity to study initial creek formation and evolution (Dale et al., 2018;

72 Vandenbruwaene et al., 2012).

Studying creek formation and the topographic evolution of MR sites would provide an improved understanding of the evolution of the physical system and function in saltmarsh restoration and creation schemes, and deliver empirical data for enhanced knowledge on 
investigated these features, with most studies focusing on the movement and redistribution of sediment (e.g. Dale et al., 2017; Rotman et al., 2008). Previous studies that investigated topographic variability in MR sites (e.g. Dale et al., 2018; Lawrence et al., 2018) have relied on relatively coarse resolution remote sensing and surveying data, such as differential GPS and LiDAR (Light Detection and Ranging) datasets. In a recent study, Chirol et al., (2018) proposed the use of a semi-automated creek extraction algorithm to monitor creek development within newly inundated intertidal settings, based on LiDAR data. However, LiDAR is typically available at meter horizontal resolution, and can include a large vertical error in waterlogged (e.g. Wang et al., 2009) and vegetated areas; it has been suggested the vertical error can range between 25 to $60 \mathrm{~cm}$ in densely vegetated parts of the intertidal zone (Enwright et al., 2018). Given that both waterlogged and vegetated conditions are typical of intertidal marsh environments small, but important, changes in elevation which may relate to initial creek formation and topographic evolution could be missed via this approach.

One solution to these limitations was proposed by Dale et al., (2018) through the use of a high resolution digital surface model (DSM), produced using the emerging low-cost photogrammetric method Structure-from-Motion (SFM), derived from images taken by a small-Unmanned Aerial System (sUAS). Although these authors demonstrated the suitability of this technique for reconstruction of the surface geometry within an intertidal marsh setting, they failed to consider the application of multiple surveys to evaluate morphological change and development in a response to tidal inundation. Here, we present a re-evaluation of the model of Dale et al., (2018) in comparison to two further surveys, taken annually, to consider the changes in intertidal morphology at the Medmerry Managed Realignment Site, West Sussex, UK (Figure 1). Specifically, this study innovatively assesses repeat surveys to investigate the erosion and accretion of sediment, the topographic variability and evolution of creek systems at high (centimetre) resolution. This analysis has been conducted in higher resolution than has previously been possible using techniques such as LiDAR, GPS or traditional ground surveying using levels. Additionally, we evaluate the application of orthophotography and SFM derived DSMs of evolving intertidal marsh environments to describe the formation, evolution and characteristics of topographic features, such as drainage networks, which may have the potential for use not only in recently inundated sites but in older MR sites and natural intertidal settings. 

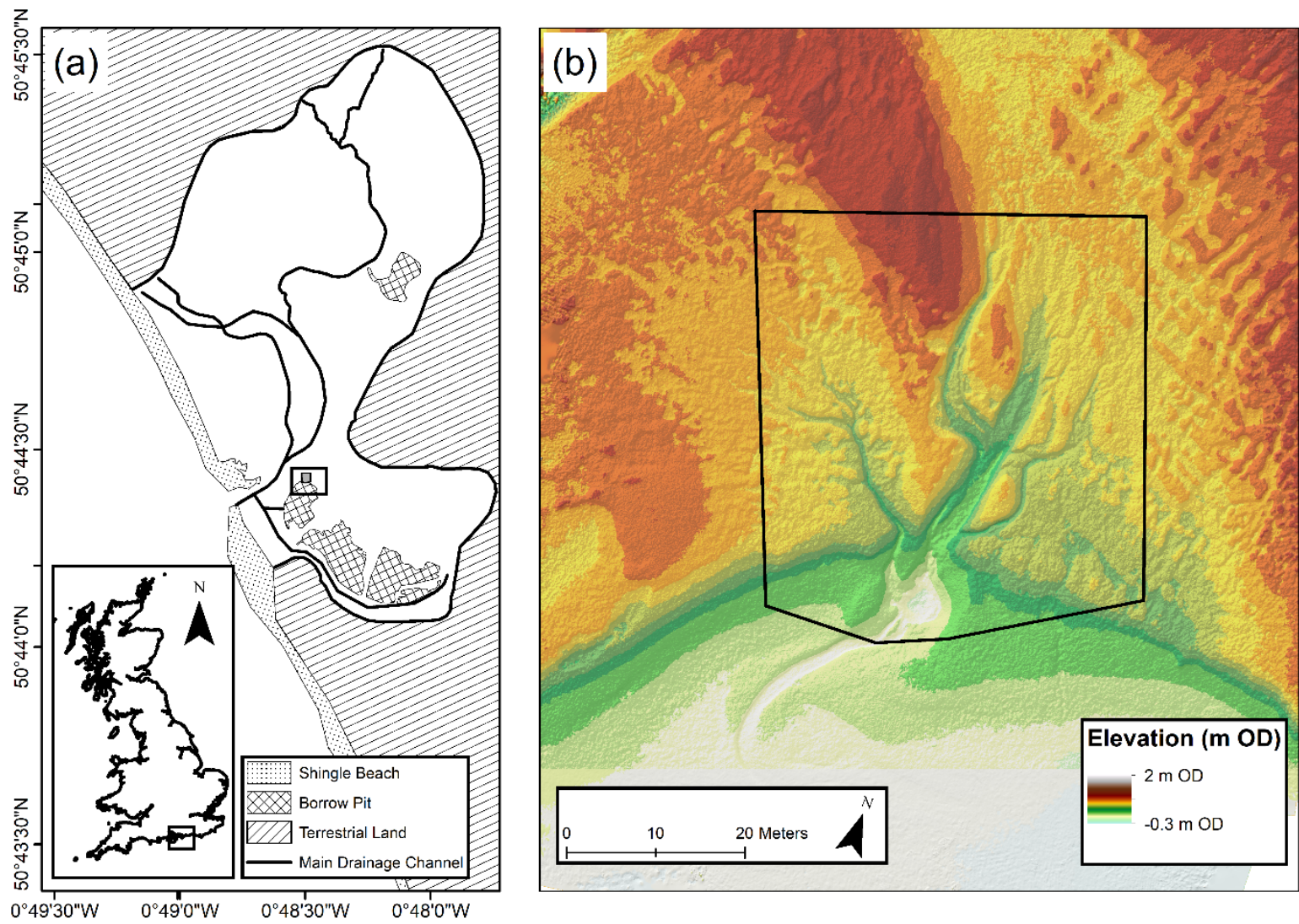

113 Figure 1: (a) The Medmerry Managed Realignment Site, UK setting (insert) and study area marked by the grey box. (b) The study area overlaying the 2017 DSM.

\section{Methods}

\subsection{Study Site}

The Medmerry Managed Realignment Site is located in the eastern Solent on the south coast of the UK (Figure 1). The site was constructed to compensate for intertidal habitat loss elsewhere in the region, and to locally improve the level of coastal flood defence, through the creation of 300 hectares of new intertidal habitat. New defences, $7 \mathrm{~km}$ in length, were constructed out of material sourced and extracted from within the site in order to create areas of lower elevation, known as borrow pits, to encourage a range of intertidal habitat. The site was breached in September 2013 through a single inlet cut in the former shingle barrier beach flood defences, forming a semi-diurnal mesotidal system. 
Here, we present analysis of the morphological development of the higher elevation bank leading into a near-breach infilling borrow pit (Dale et al., 2017), where creeks had formed following site breaching (Figure 1 ) as a result of the collapse of sub-surface soil pipes (Dale et al., 2018). This site was selected as it allowed measurements to be taken in a rapidly evolving environment, and permitted comparisons to be made through a re-evaluation of the sUAS survey taken in July 2016 by Dale et al., (2018) and two new surveys covering the same $1995.91 \mathrm{~m}^{2}$ study area, taken in September 2017 and July 2018.

\section{2 sUAS Image Acquisition}

For the three aforementioned surveys at the Medmerry site, aerial images were captured from sequential flights over an hour-long period using a crosshatched flight plan. A DJI Inspire 1 sUAS was deployed at a target altitude of $20 \mathrm{~m}$ above ground level. Images were captured using a DJI Zenmuse X3, 3-band RGB camera with a focal length of $20 \mathrm{~mm}$. Surveys were conducted during consistent weather conditions (temperature $12-18{ }^{\circ} \mathrm{C}$, wind speed 14-19 km/h, sun with minor cloud cover). A $5 \mathrm{~m}$ survey line spacing ensured maximum image overlap (>80\%), and complete coverage of the survey area. Ground control points (GCPs) were recorded using differential global positioning system (dGPS) measurements taken by a Leica AS19 GNSS antenna, a Leica Viva GS10 GPS receiver and a Leica CS15 controller. Raw GPS measurements were imported into Leica Geo Office (version 8.3). Network Receiver Independent Exchange Format (RINEX) correction data were obtained from Leica Smart Net UK \& Ireland (http://uk.smartnet-eu.com/rinex-download_148.htm), and used to correct the raw GPS data. Leica Geo Office reported the positional quality (XYZ) for all dGPS points as $<0.02 \mathrm{~m}$. Seven GCPs were captured in 2016 and 2018, and nine were taken in 2017 (Table 1) for the purposes of image matching.

\section{3 sUAS Image Processing and Analysis}

Dense point clouds were produced from optimised camera locations using mild-depth filtering to ensure small and important details were preserved using Agisoft Photoscan (v1.2.5). 319 images were acquired in 2016, 318 images in 2017 and 437 in 2018. From the dense point cloud output both orthomosaic images and DSMs were produced. Previous studies have reported a central "doming" effect (e.g. James and Robson 2014), which may have been amplified in this study due to the low flight height. To minimise this effect, fisheye correction and camera alignment optimisation were applied. Additional ground check points were collected using dGPS to act as an independent assessment of model 
quality; six check points were collected in 2016, twelve in 2017 and ten in 2018 for the purposes of error assessment.

DSMs of Difference (DoD) analysis was performed to compare differences between the two modelled surfaces. When comparing two different DSMs, it is important to consider the uncertainties and potential error propagation between the two DSMs. It is, therefore, necessary to omit any change smaller than a specified level of detection (LoD) from the analysis (James et al., 2017). The LoD can be defined as (Lane et al., 2003):

$\operatorname{LoD}= \pm \mathrm{t}\left(\sigma_{\mathrm{z} 1}{ }^{2}+\sigma_{\mathrm{zz}}{ }^{2}\right)^{1 / 2}$

[Equation 1]

where $\sigma_{z 1}$ and $\sigma_{z 2}$ are measures of the vertical error of the two DSMs, in this case the vertical standard deviations of error, and $t$ is the required level of confidence ( $95 \%$ used here).

Changes in topographic variability were assessed via analysis of the surface heterogeneity, also known as the rugosity, calculated as the standard deviation of the elevation in a $3 \times 3$ pixel moving window (after Lawrence et al., 2018). To quantify the difference in the creek networks between the two years, creeks were classified into creek orders according to Strahler (1957) stream order analysis, with the first order assigned to the smallest (source) creek with order increments with each downstream intersection. Creeks were detected and split into the corresponding order category in ArcMap (v10.5.1) as a result of the flow direction and accumulation. DSMs were filled prior to analysis to remove any sinks, and a flow accumulation threshold value of 5000 was used in order to create the creek network. The resulting creek network was visually confirmed via a comparison with the orthophotograph and the total number, total length, density (total length per survey area), average length and length of the longest creek identified for each order. Differences in total number of creeks in each order were analysed using $\mathrm{Chi}^{2}$ (Pearson) analysis. The difference in creek length between each order and differences in the rugosity were analysed via MannWhitney $U$ Tests as data were not normally distributed (Anderson-Darling, $p<0.05$ ). Statistical analysis was performed in Minitab (v18). 
196 Table 1: Images analysed, number of ground control points (GCPs), number of check points, resolution of the orthophotography and digital

197 surface models (DSMs), and calculated root-mean-square error between the DSMs and check points for the 2016, 2017 and 2018 surveys.

198

\begin{tabular}{lllllllcc}
\hline & $\begin{array}{l}\text { Images } \\
\text { Analysed }\end{array}$ & No. of GCPs & $\begin{array}{l}\text { No. of } \\
\text { Check } \\
\text { Points }\end{array}$ & $\begin{array}{l}\text { Orthophotography } \\
\text { Resolution }(\mathrm{m} / \text { pix })\end{array}$ & $\begin{array}{l}\text { DSM Resolution } \\
(\mathrm{m} / \text { pix) }\end{array}$ & X Error (m) & Y Error (m) & Z Error (m) \\
\hline 2016 & 319 & 7 & 6 & 0.00658 & 0.0263 & 0.0282 & 0.0329 \\
2017 & 318 & 9 & 12 & 0.0103 & 0.0412 & 0.1043 & 0.0637 & 0.0704 \\
2018 & 437 & 7 & 10 & 0.0112 & 0.0448 & 0.0411 & 0.0551 & 0.1571 \\
\hline
\end{tabular}




\section{Results and Discussion}

200

\subsection{Model Output and Accuracy}

202

The reported resolution of the DSMs and the RGB orthorectified images are reported in Table 1. Comparisons, through RMSE values, between the DSMs and independent check points are presented in Table 1 , and indicate an acceptable degree of confidence in the accuracy of the models in accordance with the range reported by Tonkin and Midgley 207 (2016).

208

\subsection{Topographic Change and Variability}

210

The distribution of bed elevations (Figure 2) showed an increase over time, suggesting material was accreted across the study area. This is particularly the case between 2017 and 2018, when a broad, more platykurtic, distribution of elevations were observed, indicating a considerable increase in the accretion of sediment. Comparisons of the change in elevation, through DoD analysis (Figure 3), indicated that in the borrow pit at the southern end of the survey area elevation increased by up to $85 \mathrm{~cm}$ over the two years. This rate of accretion is

217 more than double the annual accretion rate of $15.2 \mathrm{~cm}$ per year measured by Dale et al., 218 (2017) between November 2014 and October 2015, at the same site, using an altimeter 219 system.

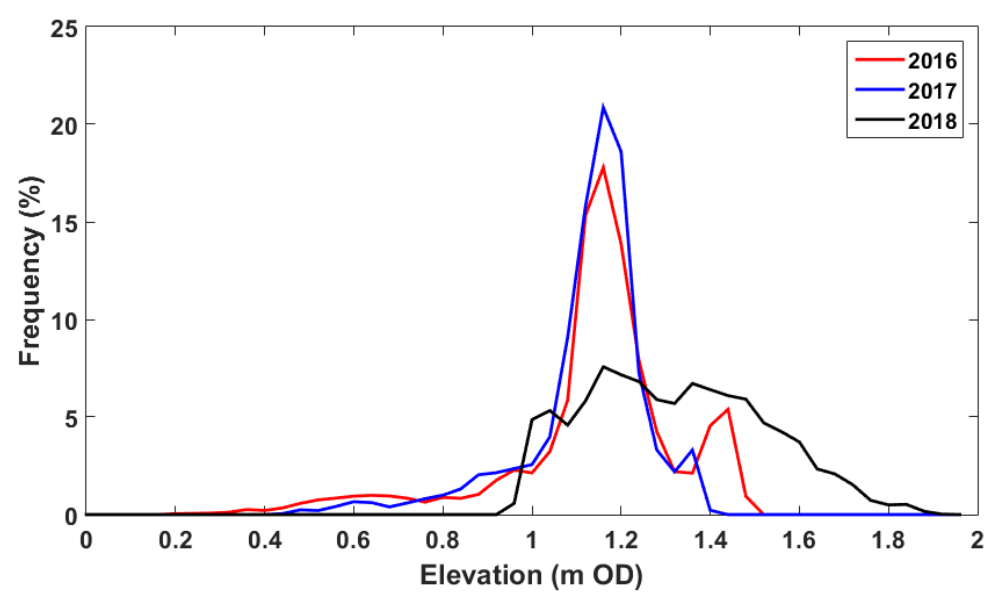

Figure 2: Distribution of elevations for the 2016 (red), 2017 (blue) and 2018 (black) DSMs. 
(a)

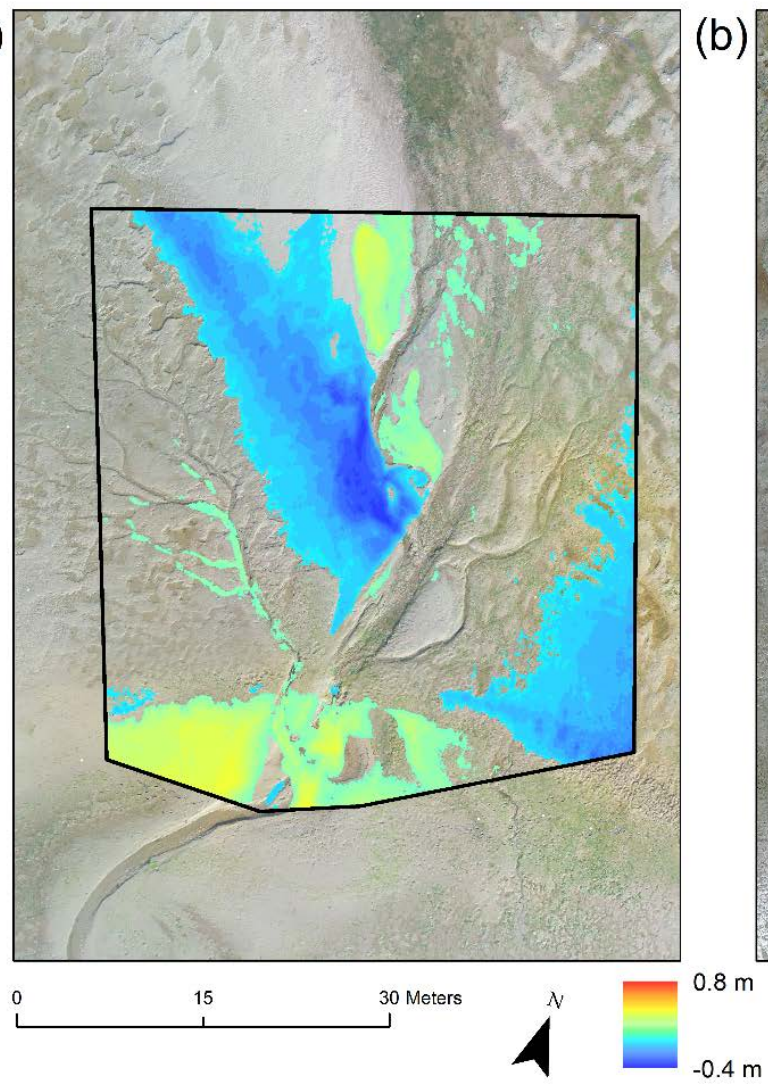

(b)

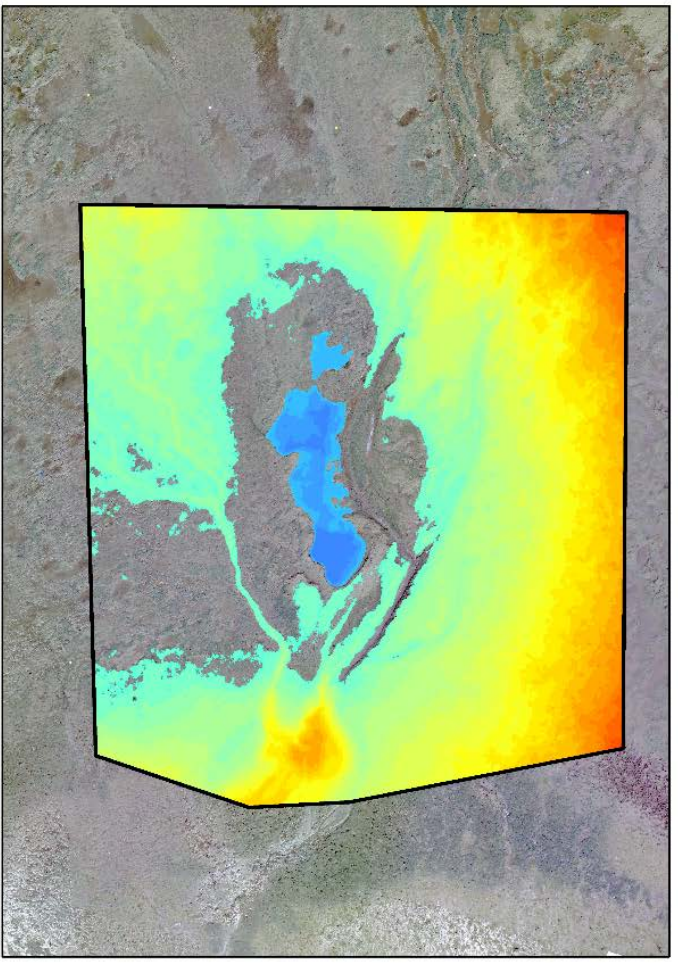

$0.4 \mathrm{~m}$

223 Figure 3: DSMs of Difference analysis of (a) the 2017 survey minus the 2016 survey overlying the 2017 orthophotograph and (b) the 2018 survey minus the 2017 survey overlying the 2018 orthophotograph. Blue is erosion and green to red is deposition.

227 On the bank, bed elevation decreased in the centre of surveyed area by 20 to $30 \mathrm{~cm}$ between 2016 and 2017, with the exception of a smaller patch of accretion to the north of the main areas of sediment loss (Figure 3a); given that the prevailing wind is from the southwest it is like that the eroded sediment has been remobilised, transported and deposited by locally induced wave activity. However, only in $34.39 \%$ of the entire 1995.91 $\mathrm{m}^{2}$ surveyed area was the recorded change in elevation outside the LoD. Erosion was measured in $65 \%$ of this area, equivalent to $22.53 \%$ of the entire survey area, whereas accretion above the LoD was measured in $11.86 \%$ of the entire survey area.

In contrast to the 2016-2017 DoD, between the 2017 and 2018 surveys $76.97 \%$ of the area investigated experienced a change in elevation beyond the LoD. Of this area, only $4.44 \%$ (3.41\% of the total area) experienced erosion, which occurred within the centre of the bank (Figure $3 b$ ). Accretion was observed across the rest of the bank, with up to $80 \mathrm{~cm}$ of sediment being deposited on the north-eastern side of the surveyed area. This increase in sediment accumulation is likely to be the result of changes in the inlet morphology, 
following the processes of coastal catch up as the beach rapidly adjusts to the likely position, had it not been fixed and artificially maintained since around 1900. Moreover,

244 Dornbusch and Mylroie (2017) estimated that prior to the beach position being fixed it was retreating at a rate of $1.5 \mathrm{~m} /$ year. Following site breaching the inlet cut in the shingle barrier beach has widened and rolled back. Consequently the exposure of this site to larger coastal processes and externally generated waves, opposed to waves generated within the fetch and depth limited system, is likely to have increased. The interaction between these waves and relic hedgerows and other surrounding topographical features was suggested by Dale et al., (2017) to be the source of sediment to this site, and an increase in wave energy is likely to result in increased supply of sediment.

252

Mean rugosity, which has been shown to correlate positively with creek density (Lawrence et al., 2018), increased $(2016=0.0021 ; 2017=0.0024 ; 2018=0.0026)$ and differed significantly $(p<0.001)$ between years, suggesting an increase in topographic complexity over time. These results are indicative of an increase in surface drainage features and a reduction in the opportunity for water to pool and accumulate, which may enhance the physical, chemical and biological edaphic conditions, advancing opportunities for saltmarsh vegetation to become established (e.g. Mossman et al., 2012). Lawrence et al., (2018) compared the topography of $19 \mathrm{MR}$ sites to surrounding natural saltmarshes and agricultural fields, finding that the MR sites were more similar to the terrestrial fields in terms of topographic variability. These authors also suggested that there was no relationship between age and the topographic evolution. However, results presented in this study from the Medmerry site indicate that there has been some topographic evolution as the site responds to intertidal inundation, although the rate, spatial and temporal scale of this response requires further investigation. This is particularly true of sites that have experienced different levels of pre-breach landscaping, such as ploughing or the construction of areas of lower elevation (e.g. Cotton et al., 2008), to maximise topographic variability. Comparisons of the temporal and spatial change in topography is also required, comparing both within and between MR sites, to assess the influence of different hydrodynamics and variations in the supply of suspended sediment on the topographic and morphological evolution.

\subsection{Evolution of Creek Morphology}

277 In 2016, 291 creeks were classified into five orders, whilst 117 and 112 creeks were divided

278 into four orders in 2017 and 2018 respectively (Table 2, Figure 4). Chi ${ }^{2}$ analysis, performed 
279 on the orders 1 to 4 as no fifth order creeks were detected after 2016, indicated a

280 statistically significant association between the individual surveys and creek abundance $\left(\chi^{2}=\right.$ 281 18.05, $p=0.006$ ). A higher creek density of $0.44 \mathrm{~m} / \mathrm{m}^{2}$ was measured in 2016, compared to $2820.27 \mathrm{~m} / \mathrm{m}^{2}$ measured in 2017 and 2018, suggesting that some branches have become more 283 prominent in draining the intertidal area. This process appears to be ongoing, especially in 284 the creek system on the western side of the study area, which was noticeably less apparent 285 in the orthophotography and visually whilst during sampling. Only first order creek length 286 between 2016 and 2017 differed significantly $(p<0.001$, Table 2$)$. 
Table 2: Summary of creek order analysis for the 2016, 2017 and 2018 surveys. Significant differences in creek length between the two surveys for each order were assessed via a Mann-Whitney U Test ( $p$ values reported) at the $95 \%$ confidence interval.

\begin{tabular}{|c|c|c|c|c|c|c|c|}
\hline & & First & Second & Third & Fourth & Fifth & Total \\
\hline \multirow{3}{*}{ Total Creeks } & 2016 & 158 & 75 & 23 & 31 & 4 & 291 \\
\hline & 2017 & 65 & 32 & 19 & 1 & & 117 \\
\hline & 2018 & 59 & 32 & 15 & 6 & & 112 \\
\hline \multirow{3}{*}{$\begin{array}{l}\text { Total Length } \\
(\mathrm{m})\end{array}$} & 2016 & 498.26 & 228.96 & 73.39 & 70.25 & 5.05 & 875.91 \\
\hline & 2017 & 312.07 & 122.3 & 97.05 & 3.95 & & 535.37 \\
\hline & 2018 & 310.7 & 133.18 & 69.83 & 18.06 & & 531.77 \\
\hline \multirow{3}{*}{$\begin{array}{l}\text { Density } \\
\left(\mathrm{m} / \mathrm{m}^{2}\right)\end{array}$} & 2016 & 0.25 & 0.11 & 0.04 & 0.04 & 0.002 & 0.44 \\
\hline & 2017 & 0.16 & 0.06 & 0.05 & 0.002 & & 0.27 \\
\hline & 2018 & 0.16 & 0.07 & 0.03 & 0.01 & & 0.27 \\
\hline \multirow{3}{*}{$\begin{array}{l}\text { Average Length } \\
( \pm s t d)(\mathrm{m})\end{array}$} & 2016 & $3.15 \pm 2.99$ & $3.05 \pm 2.33$ & $3.19 \pm 2.04$ & $2.27 \pm 2.07$ & $1.26 \pm 0.81$ & $12.92 \pm 2.36$ \\
\hline & 2017 & $4.8 \pm 3.54$ & $3.82 \pm 3.43$ & $5.11 \pm 4.21$ & 3.95 & & $17.68 \pm 3.73$ \\
\hline & 2018 & $5.27 \pm 4.60$ & $4.16 \pm 4.47$ & $4.66 \pm 3.63$ & $3.01 \pm 1.72$ & & $4.75 \pm 4.08$ \\
\hline \multirow{3}{*}{$\begin{array}{l}\text { Longest Creek } \\
\text { (m) }\end{array}$} & 2016 & 14.76 & 9.27 & 8.99 & 9.37 & 2.22 & \\
\hline & 2017 & 16.62 & 12.57 & 17.72 & 3.95 & & \\
\hline & 2018 & 22.87 & 16.7 & 13.65 & 5 & & \\
\hline \multirow{2}{*}{$\begin{array}{l}\text { Mann-Whitney } \\
\text { U Test } p \text { value } \\
\text { (length) }\end{array}$} & 2016 - 2017 & $<0.001$ & 0.603 & 0.143 & & & \\
\hline & 2017 - 2018 & 0.893 & 0.532 & 0.89 & & & \\
\hline
\end{tabular}



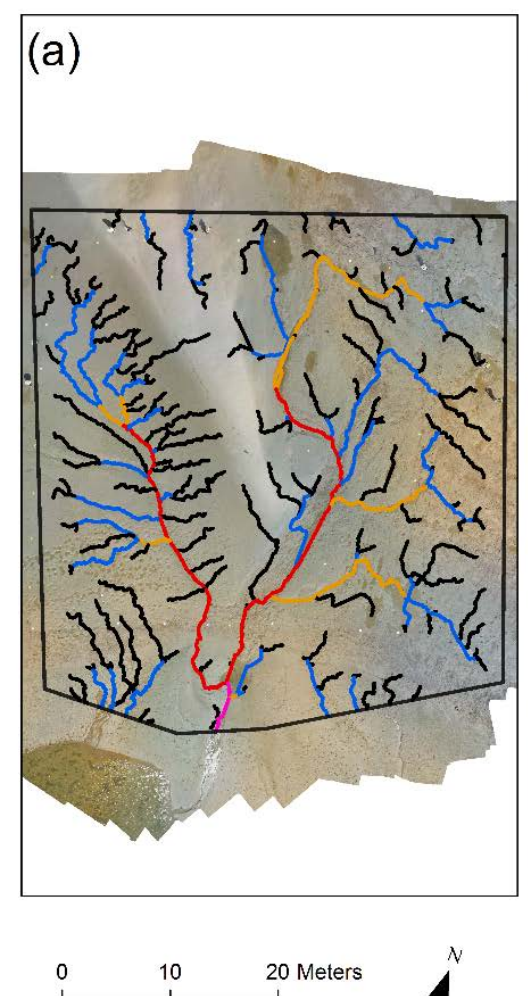

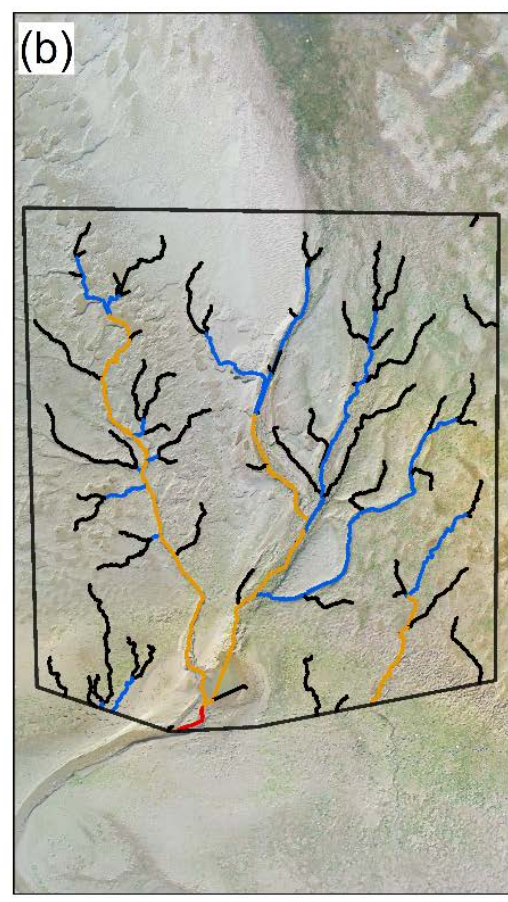

Stream Order
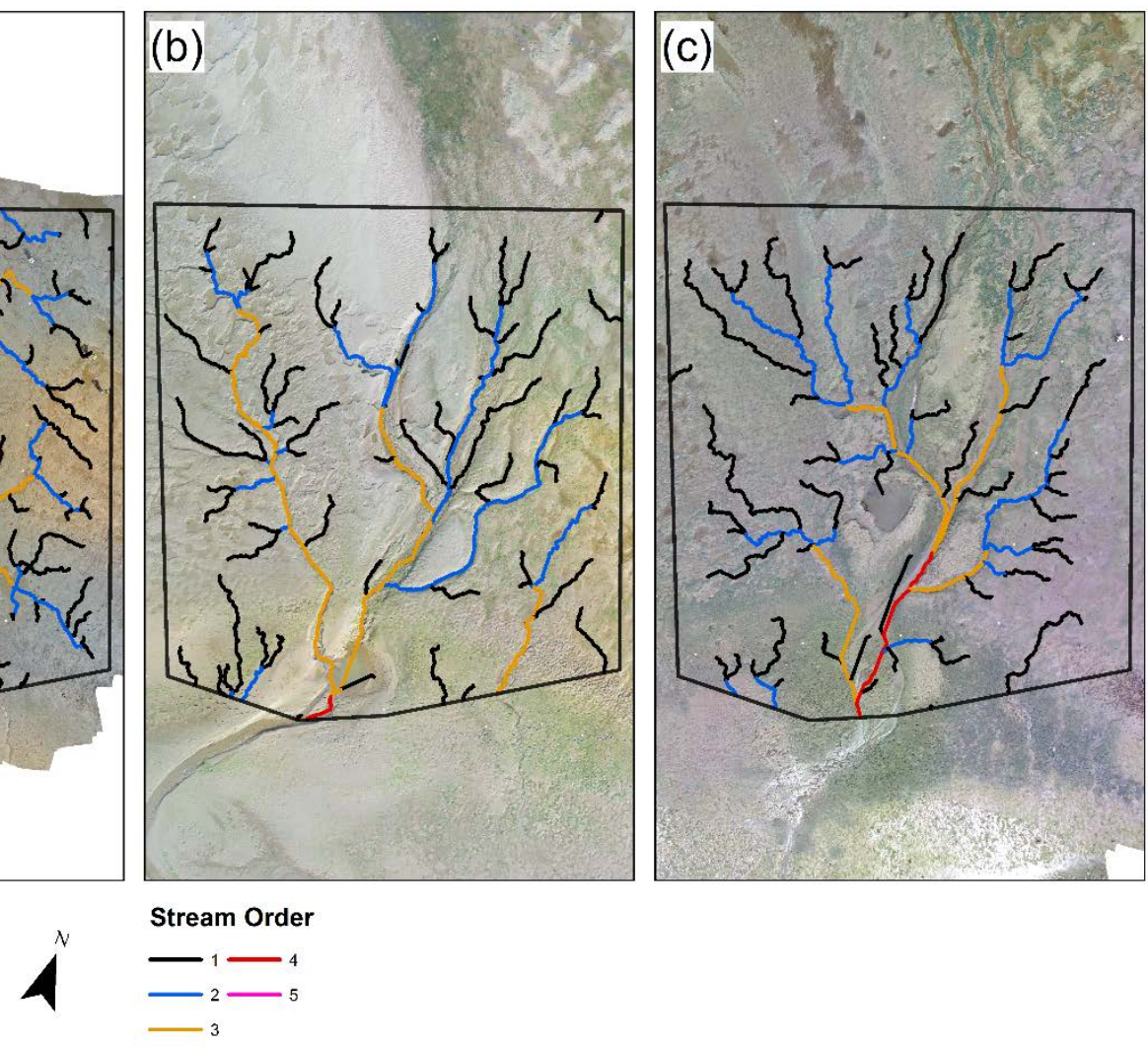

Figure 4: Stream order analysis of (a) the 2016 survey, (b) the 2017 survey and (c) the 2018 survey (after Strahler 1957). The first order (one) is assigned to the smallest (source) creek with order increments with each downstream intersection.

In 2016, a number of first and second order creeks appeared to run perpendicular to the direction of higher order (fourth and fifth order) creeks. The development of drainage features in MR sites has previously been related to the pre-existing landscape features (French and Stoddart 1992), such as plough lines, along with the sediment properties such as the drainage characteristics and the sub-surface stratigraphy, tidal energy, and the surface gradient of the intertidal zone (e.g. D'Alpaos et al., 2007; Spencer and Harvey 2012). As a result, it has been suggested that the pre-existing terrestrial topography and drainage features may be retained for many years and, in some case, remain as permanent features (Bowron et al., 2011; Lawrence et al., 2018). On visual examination of the orthophotographs from Medmerry, the perpendicular channels appear to be relic plough lines from the sites former agricultural land use; the area around the study site was last harvested two weeks before site breaching. However, the influence of these features decreased with time, with the lower order creeks detected in 2017 and 2018 appearing to have cut through the plough lines and to be considerably closer in orientation to the higher order drainage channels. features in sites that are exposed to lower magnitude hydrodynamic processes and forces. 
312 The influence different pre-breach conditions, such as plough lines, tyre tracks from site

313 construction machinery, other pre-existing drainage features, also requires further

314 investigation. From this, sites could be designed to incorporate these features into the post-

315 site inundation evolution, maximising not only the sites morphological evolution but the

316 ecological development. Consequently, the ecosystem services such as provision of habitat

317 and flood defence provided by could also be enhanced.

318

319

320

321

322

323

Predictive models (e.g. Allen 2000) and measurement data do exist on the topographic and

324 morphological change in intertidal wetland environments following intertidal inundation.

325 However, the majority of these measurement data are limited to a single point or small $(\mathrm{cm}$ to $\mathrm{m}$ ) spatial area (e.g. Dale et al., 2017; Ni et al., 2014), obtained from sediment core records and do not provide a detail on the inter-annual variability (e.g. Cundy et al., 2002; Spencer et al., 2017), or have relied on remote sensing data such as aerial photography and LiDAR (Krolik-Root et al., 2015; Lawrence et al., 2018). As a result of the spatio-temporal limitations, and the vertical and horizontal resolution which may be too coarse to identify small, but important, variations in topography, the topographical evolution of MR sites is not fully understood. The use of sUAS surveys and SfM analysis, as demonstrated the Medmerry Managed Realignment Site herein, provides an alternative method of evaluating the fine-scale evolution and morphodynamics of intertidal wetland environments to address these shortcomings. The ability of sUAS surveys to capture change at the centimetre scale over a larger area provides researchers with the ability to closely monitor the evolution of these developing systems. A further advantage of sUAS surveys in the analysis of intertidal morphodynamics is that they are relatively simple and inexpensive to deploy. This allows sUAS surveys to be used to investigate morphological evolution at multiple sites, as has been the case in LiDAR based studies (e.g. Chirol et al., 2018; Lawrence et al., 2018), but at higher resolution, increased temporal frequency and without the associated error.

Intertidal creek networks play an important role in natural saltmarsh environments as they regulate site drainage, act as a conduit for water, sediment and nutrients between the marsh and the surrounding coastal environment, and provide habitats and nursery grounds for fish species. Despite the importance of these features, previous studies into creek evolution in MR sites (e.g. Chirol et al., 2018; Lawrence et al., 2018) have relied on single topographic surveys. The use of sUAS surveying allows for repeat measurements without the time or financial costs associated with other remote sensing techniques. As a result, 
sUAS surveys can be used to assess morphodynamics at range of timescales (tidal, monthly, annual, multi-annual), and therefore at different corresponding spatio-temporal scales. Furthermore, the application of sUAS surveying may also be applicable to help understand vegetation development and ecosystem functioning in relation to a site's morphological development through vegetation and habitat mapping, as previously performed in other settings elsewhere (e.g. Belluco et al., 2006; Strong et al., 2017). This potential application, including multi-spectral vegetation analysis, should form the basis of future research focussed on the value and use of sUAS in intertidal settings.

The movement of sediment within these developing MR systems, presented here through DoD analysis, has been shown to be detectable using sUAS analysis providing the levels of accretion and erosion are above the survey's LoD. This is likely to be the case in newly inundated intertidal environments such as MR sites; predictive models and measurements data, including the measurements presented here, have suggested high levels of accretion should be expected as the site adjusts to tidal inundation (e.g. Vandenbruwaene et al., 2011). Moreover, given the high accuracy and precision of the DSM, it may as also be suitable for annual (or more frequent) comparisons in older and natural sites, where bed elevation may be relatively stable in relation to the hydroperiod or sediment supply could be lower (e.g. Deloffre et al., 2007; Kirby 1990). The error accounted for in this sUAS approach is considerably lower than the error associated with traditional remote sensing techniques such as LiDAR. For example, Enwright et al., (2018) reported an error of up to 60 $\mathrm{cm}$ for LiDAR data, compared to up to $15 \mathrm{~cm}$ calculated in this study. Furthermore, this technique may also be suitable for mapping marsh loss and retreat, particularly mashes that are cliffed or fragmented (Allen and Pye 1992; Baily and Pearson 2007).

\section{Conclusions}

This paper demonstrates the suitability of using sUAS and SfM analysis to monitor the morphodynamics and evolution of creek networks in restored intertidal wetlands, at a resolution that has not been possible previously. sUAS surveys are relatively inexpensive, and can easily be implemented, making them a useful tool to monitor morphological development in intertidal environments. Whilst the success of using this technique may be limited in some settings due to concerns regarding the error associated with these measurements, this error is considerably lower than the error reported using other remote sensing techniques such as LiDAR. The potential applications of using DSMs created from sUAS surveys, namely stream order, DoD and topographic analysis, are presented here from the Medmerry Managed Realignment Site. Results indicate that sediment is being imported 
and locally remobilised, alongside an increase in topographic variability and the development of the intertidal drainage system. From these findings, and additional studies of this nature, the importance of designing morphology prior to site breaching to ensure the successful colonisation of intertidal habitat can be quantified further. Furthermore, the evolution of established creek networks in natural marshes and intertidal wetlands can now be easily investigated in higher spatial and temporal resolution, to $\mathrm{cm}$ accuracy, than was previously possible. This will inform managers, engineers and policy makers and aid the management of wetland environments to ensure the provision of ecosystem services and to determine the vulnerability of these habitats from future climate change, sea level rise and anthropogenic forcing.

\section{Acknowledgements}

399 The authors would like to thank: two anonymous reviewers for their supportive and

400 insightful comments, David Stansbury (University of Brighton) for his assistance with

401 correcting dGPS data, Robert Strick (University of Brighton) for his advice on data analysis

402 and the School of Environment and Technology, University of Brighton for financial support.

403 JD would like to thank Andrew Cundy, David Nash and Callum Firth for their guidance during

404 his studentship. Both JD and CS would like to thank the Environment Agency (UK) for

405 funding their studentships.

406

\section{Author's Contribution}

408 JD performed all steps in analysing and interpreting the data and writing the initial

409 manuscript, and participated in the sUAS surveys to acquire the images.

410 NGB performed the sUAS surveys, assisted in model production and contributed towards 411 editing the manuscript.

412 CJS performed the image processing to produce the models and contributed towards 413 planning the data analysis.

414 HMB participated in the final editing of the manuscript and contributed towards the study 415 design.

416 All authors have read and approved the manuscript. 


\section{Declaration of interests}

419 The authors declare that they have no known competing financial interests or personal

420 relationships that could have appeared to influence the work reported in this paper.

421

422

423 


\section{References}

425

426

427

428

429

430

431

432

433

434

435

436

437

438

439

440

441

442

443

444

445

446

447

448

449

450

451

452

453

454

455

456

457

458

459

460

461

462

463

464

465

466

467

468

Allen, J.; Pye, K. Coastal saltmarshes: their nature and importance. in: Allen J., Pye K., eds. Saltmarshes: Morphodynamics, conservation and engineering significance. Cambridge: Cambridge University Press; 1992

Allen, J.R.L. Morphodynamics of Holocene salt marshes: a review sketch from the Atlantic and Southern North Sea coasts of Europe. Quaternary Science Reviews. 19:1155$1231 ; 2000$

Baily, B.; Pearson, A.W. Change detection mapping and analysis of salt marsh areas of central southern England from Hurst Castle Spit to Pagham Harbour. Journal of Coastal Research. 23:1549-+; 2007

Belluco, E.; Camuffo, M.; Ferrari, S.; Modenese, L.; Silvestri, S.; Marani, A.; Marani, M. Mapping salt-marsh vegetation by multispectral and hyperspectral remote sensing. Remote Sensing of Environment. 105:54-67; 2006

Bowron, T.; Neatt, N.; van Proosdij, D.; Lundholm, J.; Graham, J. Macro-Tidal Salt Marsh Ecosystem Response to Culvert Expansion. Restoration Ecology. 19:307-322; 2011

Chirol, C.; Haigh, I.D.; Pontee, N.; Thompson, C.E.; Gallop, S.L. Parametrizing tidal creek morphology in mature saltmarshes using semi-automated extraction from lidar. Remote Sensing of Environment. 209:291-311; 2018

Costanza, R.; d'Arge, R.; deGroot, R.; Farber, S.; Grasso, M.; Hannon, B.; Limburg, K.; Naeem, S.; O'Neill, R.V.; Paruelo, J.; Raskin, R.G.; Sutton, P.; van den Belt, M. The value of the world's ecosystem services and natural capital. Nature. 387:253-260; 1997

Cotton, J.; Brown, S.; Staley, P.; Murby, P.; Badley, J. Future monitoring at coastal realignment sites: Lessons learnt from the freiston flood defence scheme. Flood and Coastal Management Conference. University of Manchester; 2008

Cundy, A.B.; Long, A.J.; Hill, C.T.; Spencer, C.; Croudace, I.W. Sedimentary response of Pagham Harbour, southern England to barrier breaching in AD 1910. Geomorphology. 46:163-176; 2002

D'Alpaos, A.; Lanzoni, S.; Marani, M.; Bonornetto, A.; Cecconi, G.; Rinaldo, A. Spontaneous tidal network formation within a constructed salt marsh: Observations and morphodynamic modelling. Geomorphology. 91:186-197; 2007

Dale, J.; Burgess, H.M.; Burnside, N.G.; Kilkie, P.; Nash, D.J.; Cundy, A.B. The evolution of embryonic creek systems in a recently inundated large open coast managed realignment site. Anthropocene Coasts. 1:16-33; 2018

Dale, J.; Burgess, H.M.; Cundy, A.B. Sedimentation rhythms and hydrodynamics in two engineered environments in an open coast managed realignment site. Marine Geology. 383:120-131; 2017

Deloffre, J.; Verney, R.; Lafite, R.; Lesueur, P.; Lesourd, S.; Cundy, A.B. Sedimentation on intertidal mudflats in the lower part of macrotidal estuaries: Sedimentation rhythms and their preservation. Marine Geology. 241:19-32; 2007

Dornbusch, U.; Mylroie, P. Examples of Coastal Catch-up Including Barrier Roll-back, Marsh and Brick-earth Cliff Erosion in Southeast England. Coasts, Marine Structures and Breakwaters 2017; 2017

Duarte, C.M.; Dennison, W.C.; Orth, R.J.W.; Carruthers, T.J.B. The charisma of coastal ecosystems: Addressing the imbalance. Estuaries and Coasts. 31:233-238; 2008 
480

481

482

483

484

485

486

487

488

489

490

491

492

493

494

495

496

497

498

499

500

501

502

503

504

505

506

507

508

509

510

511

512

513

514

515

Enwright, N.M.; Wang, L.; Borchert, S.M.; Day, R.H.; Feher, L.C.; Osland, M.J. The Impact of Lidar Elevation Uncertainty on Mapping Intertidal Habitats on Barrier Islands. Remote Sensing. 10; 2018

Fagherazzi, S.; Furbish, D.J. On the shape and widening of salt marsh creeks. Journal of Geophysical Research-Oceans. 106:991-1003; 2001

French, J.R.; Stoddart, D.R. Hydrodynamics of salt marsh creek systems: Implications for marsh morphological development and material exchange. Earth Surface Processes and Landforms. 17:235-252; 1992

Garbutt, R.A.; Reading, C.J.; Wolters, M.; Gray, A.J.; Rothery, P. Monitoring the development of intertidal habitats on former agricultural land after the managed realignment of coastal defences at Tollesbury, Essex, UK. Marine Pollution Bulletin. 53:155-164; 2006

James, M.R.; Robson, S. Mitigating systematic error in topographic models derived from UAV and ground-based image networks. Earth Surface Processes and Landforms. 39:1413-1420; 2014

James, M.R.; Robson, S.; Smith, M.W. 3-D uncertainty-based topographic change detection with structure-from-motion photogrammetry: precision maps for ground control and directly georeferenced surveys. Earth Surface Processes and Landforms. 42:1769$1788 ; 2017$

Kirby, R. The sediment budget of the erosional intertidal zone of the Medway Estuary, Kent. Proceedings of the Geologists' Association. 101:63-77; 1990

Krolik-Root, C.; Stansbury, D.L.; Burnside, N.G. Effective LiDAR-based modelling and visualisation of managed retreat scenarios for coastal planning: An example from the southern UK. Ocean \& Coastal Management. 114:164-174; 2015

Lane, S.N.; Westaway, R.M.; Hicks, D.M. Estimation of erosion and deposition volumes in a large, gravel-bed, braided river using synoptic remote sensing. Earth Surface Processes and Landforms. 28:249-271; 2003

Lawrence, P.J.; Smith, G.R.; Sullivan, M.J.P.; Mossman, H.L. Restored saltmarshes lack the topographic diversity found in natural habitat. Ecological Engineering. 115:58-66; 2018

Lotze, H.K.; Lenihan, H.S.; Bourque, B.J.; Bradbury, R.H.; Cooke, R.G.; Kay, M.C.; Kidwell, S.M.; Kirby, M.X.; Peterson, C.H.; Jackson, J.B.C. Depletion, degradation, and recovery potential of estuaries and coastal seas. Science. 312:1806-1809; 2006

Marani, M.; Belluco, E.; D'Alpaos, A.; Defina, A.; Lanzoni, S.; Rinaldo, A. On the drainage density of tidal networks. Water Resources Research. 39; 2003

Mazik, K.; Musk, W.; Dawes, O.; Solyanko, K.; Brown, S.; Mander, L.; Elliott, M. Managed realignment as compensation for the loss of intertidal mudflat: $A$ short term solution to a long term problem? Estuarine, Coastal and Shelf Science. 90:11-20; 2010

Mossman, H.L.; Davy, A.J.; Grant, A. Does managed coastal realignment create saltmarshes with 'equivalent biological characteristics' to natural reference sites? Journal of Applied Ecology. 49:1446-1456; 2012

Ni, W.; Wang, Y.P.; Symonds, A.M.; Collins, M.B. Intertidal flat development in response to controlled embankment retreat: Freiston Shore, The Wash, UK. Marine Geology. 355:260-273; 2014

Reed, D.J.; Spencer, T.; Murray, A.L.; French, J.R.; Leonard, L. Marsh surface sediment deposition and the role of tidal creeks: Implications for created and managed coastal marshes. Journal of Coastal Conservation. 5:81-90; 1999 
Rotman, R.; Naylor, L.; McDonnell, R.; MacNiocaill, C. Sediment transport on the Freiston Shore managed realignment site: An investigation using environmental magnetism. Geomorphology. 100:241-255; 2008

Sanderson, E.W.; Foin, T.C.; Ustin, S.L. A simple empirical model of salt marsh plant spatial distributions with respect to a tidal channel network. Ecological Modelling. 139:293307; 2001

Spencer, K.L.; Carr, S.J.; Diggens, L.M.; Tempest, J.A.; Morris, M.A.; Harvey, G.L. The impact of pre-restoration land-use and disturbance on sediment structure, hydrology and the sediment geochemical environment in restored saltmarshes. Science of The Total Environment. 587-588:47-58; 2017

Spencer, K.L.; Harvey, G.L. Understanding system disturbance and ecosystem services in restored saltmarshes: Integrating physical and biogeochemical processes. Estuarine Coastal and Shelf Science. 106:23-32; 2012

Strahler, A.N. Quantitative analysis of watershed geomorphology. Transactions American Geophysical Union. 38:913-920; 1957

Strong, C.J.; Burnside, N.G.; Llewellyn, D. The potential of small-Unmanned Aircraft Systems for the rapid detection of threatened unimproved grassland communities using an Enhanced Normalized Difference Vegetation Index. Plos One. 12; 2017

Tempest, J.A.; Harvey, G.L.; Spencer, K.L. Modified sediments and subsurface hydrology in natural and recreated salt marshes and implications for delivery of ecosystem services. Hydrological Processes. 29:2346-2357; 2015

Tonkin, T.N.; Midgley, N.G. Ground-Control Networks for Image Based Surface Reconstruction: An Investigation of Optimum Survey Designs Using UAV Derived Imagery and Structure-from-Motion Photogrammetry. Remote Sensing. 8; 2016

Vandenbruwaene, W.; Maris, T.; Cox, T.J.S.; Cahoon, D.R.; Meire, P.; Temmerman, S. Sedimentation and response to sea-level rise of a restored marsh with reduced tidal exchange: Comparison with a natural tidal marsh. Geomorphology. 130:115-126; 2011

Vandenbruwaene, W.; Meire, P.; Temmerman, S. Formation and evolution of a tidal channel network within a constructed tidal marsh. Geomorphology. 151:114-125; 2012

Wang, C.; Menenti, M.; Stoll, M.P.; Feola, A.; Belluco, E.; Marani, M. Separation of Ground and Low Vegetation Signatures in LiDAR Measurements of Salt-Marsh Environments. leee Transactions on Geoscience and Remote Sensing. 47:2014-2023; 2009

Wolters, M.; Garbutt, A.; Bakker, J.P. Salt-marsh restoration: evaluating the success of deembankments in north-west Europe. Biological Conservation. 123:249-268; 2005 